\title{
Pseudomonas syringae pv. tomato Strains from New York Exhibit Virulence Attributes Intermediate Between Typical Race 0 and Race 1 Strains
}

Christine M. Kraus and Carolina Mazo-Molina, Boyce Thompson Institute for Plant Research, Ithaca, NY 14853, and Plant Pathology and Plant-Microbe Biology Section, School of Integrative Plant Science, Cornell University, Ithaca, NY 14853; Christine D. Smart, Plant Pathology and Plant-Microbe Biology Section, School of Integrative Plant Science, Cornell University; and Gregory B. Martin, Boyce Thompson Institute for Plant Research, and Plant Pathology and Plant-Microbe Biology Section, School of Integrative Plant Science, Cornell University

\begin{abstract}
Bacterial speck disease, caused by Pseudomonas syringae pv. tomato, is a persistent problem for fresh-market tomato growers in New York. Race 0 strains of this pathogen express either or both of the type III effectors AvrPto or AvrPtoB, which are recognized by tomato varieties expressing the Pto resistance gene. Pto encodes a protein kinase that activates the host immune system, thereby inhibiting bacterial multiplication and preventing disease development. Race $1 P$. syringae pv. tomato strains do not express these effectors and are virulent on tomato whether or not the variety expresses Pto. Very few fresh-market tomato varieties have the Pto gene. We collected six $P$. syringae pv. tomato strains from naturally infected tomato plants across New York in 2015 and characterized them for their virulence and for the presence of specific effectors. In experiments conducted in the greenhouse, all strains reached population

sizes in Pto-expressing tomato leaves that were intermediate between typical race 0 and race 1 strains. This phenotype has not been observed previously and suggests that the strains are recognized by Pto but such recognition is compromised by another $P$. syringae pv. tomato factor. The strains were found to encode avrPto, which is transcribed and translated. They also express $a v r P t o B$ although, as reported for other $P$. syringae pv. tomato strains, protein expression for this effector was not detectable. Deletion of avrPto from a representative New York strain allowed it to reach high populations in Pto-expressing tomato varieties, without compromising its virulence on susceptible tomato plants. Collectively, our data suggest that introgression of the Pto gene into freshmarket tomato varieties could enhance protection against extant $P$. syringae pv. tomato strains.
\end{abstract}

Bacterial speck disease, caused by Pseudomonas syringae pv. tomato, can be a serious problem for tomato production throughout the world where the crop is grown in temperate environments. The symptoms appear as small, necrotic lesions on leaflets, stems, flowers, and fruit and can greatly affect both the yield and marketability of the crop (Pedley and Martin 2003). The disease can spread quickly, especially when aided by cool, wet summers that can occur in New York and in many other tomato-growing regions (Yunis et al. 1980). In New York, large-scale processing tomato production is no longer practiced but a significant number of tomato fruit are grown for fresh consumption. Many varieties of processing tomato express the Pto gene, which confers resistance to race 0 strains of $P$. syringae pv. tomato, but few fresh-market varieties have Pto (Bosch et al. 1990; Buonaurio et al. 1996; Pedley and Martin 2003; Pitblado and MacNeill 1983).

The Pto gene encodes a cytoplasmic protein kinase which acts with Prf, a nucleotide-binding leucine-rich repeat protein, to recognize either of two unrelated $P$. syringae pv. tomato effectors (AvrPto and AvrPtoB), leading to the activation of effector-triggered immunity (ETI) (Abramovitch et al. 2003; Kim et al. 2002; Lin and Martin 2007; Martin 2012; Mathieu et al. 2014; Rosebrock et al. 2007; Salmeron et al. 1996; Shan et al. 2000). Activation of ETI is associated with various defense responses, including programmed cell death at the site of attempted infection, which suppress pathogen growth. Pto/Prf-mediated resistance has provided effective control of bacterial speck disease for several decades but recent studies have shown that $P$. syringae pv. tomato populations worldwide have shifted toward virulent race 1 strains, which can evade Pto/Prf-mediated immunity (Cai et al. 2011). Race 1 strains were first detected in 1986 in Canada and in 1993 in the United States and have

Corresponding author: G. B. Martin; E-mail: gbm7@cornell.edu

*The $\boldsymbol{e}$-Xtra logo stands for "electronic extra" and indicates that one supplementary figure and one supplementary table are published online.

Accepted for publication 18 April 2017.

C 2017 The American Phytopathological Society since become the predominant strains found in field-grown tomato (Arredondo and Davis 2000; Lawton and MacNeill 1986). These strains evade Pto/Prf recognition in three ways: they lack avrPto and avrPtoB, they express variants of these effectors that cannot be recognized by Pto/Prf, or they express only $a v r P t o B$ but do not accumulate the AvrPtoB protein (Kunkeaw et al. 2010; Lin et al. 2006). In all cases, race 1 strains cause disease symptoms and grow to high population levels in tomato cultivars expressing Pto/Prf.

Pathogens exposed to resistant cultivars are likely to be under strong selective pressure to modify the recognized effectors in order to evade ETI. "Boom and bust" cycles often occur when resistant cultivars with single, major resistance $(R)$ genes are introduced into an agronomic system to control a plant disease. Selection pressure imposed by large acreages of a resistant cultivar can quickly shift the pathogen population toward the new strain (McDonald and Linde 2002). Indeed, a study looking at the $P$. syringae pv. tomato population present in California shows that these isolates have overcome Pto/Prf-mediated resistance by mutating or regulating the expression of AvrPto and AvrPtoB (Kunkeaw et al. 2010). However, in states such as New York, where most varieties do not have Pto/Prf, selection pressure might be low. The objectives of this study were to characterize six $P$. syringae pv. tomato strains that were isolated in New York in 2015 and to assess the potential value of Pto/Prf-mediated resistance in fresh-market tomato varieties.

\section{Materials and Methods}

Isolation of $P$. syringae pv. tomato strains from the field. Between 5 and 10 P. syringae pv. tomato isolates were collected from outbreaks of bacterial speck disease in tomato fields in each of six New York counties (Fig. 1A) using King's B (KB) semiselective medium (King et al. 1954). Other P. syringae pv. tomato strains used were T1 (Almeida et al. 2009), NYT1 (Jones et al. 2015), DC3000 (Buell et al. 2003), and DC3000 $\Delta a v r$ Pto $\triangle a v r P t o B$ (Lin and Martin 2005). All $P$. syringae pv. tomato strains were stored in $20 \%$ glycerol + $60 \mathrm{mM}$ sucrose at $-80^{\circ} \mathrm{C}$.

Plant material. Tomato plants were grown in a greenhouse with $16 \mathrm{~h}$ of light at $24^{\circ} \mathrm{C}, 8 \mathrm{~h}$ of darkness at $22^{\circ} \mathrm{C}$, and $65 \%$ humidity. Sowing and transplanting were performed as described previously (Kraus et al. 2016). Seed of Arabidopsis thaliana accession 
Columbia (Col-0) were suspended in $0.1 \%$ agarose and cold stratified for 3 days at $4^{\circ} \mathrm{C}$. The plants were grown in a controlledenvironment chamber under fluorescent lighting $\left(150 \mu \mathrm{mol} \mathrm{m} \mathrm{m}^{-2} \mathrm{~s}^{-1}\right)$ with $16 \mathrm{~h}$ of light and $8 \mathrm{~h}$ of darkness at $25^{\circ} \mathrm{C}$.

Virulence assays with A. thaliana. Strains of $P$. syringae pv. tomato grown on $\mathrm{KB}$ semiselective medium were diluted in $10 \mathrm{mM}$ $\mathrm{MgCl}_{2}$ to a final concentration of $5 \times 10^{4} \mathrm{CFU} / \mathrm{ml}$. Several leaves per plant were pressure infiltrated with a needleless syringe. The development of disease symptoms was monitored for up to 1 week after infiltration. Leaf tissue samples were taken $2 \mathrm{~h}$ after infiltration (day 0 ) and 3 days later to measure bacterial populations. Three leaf discs ( $7 \mathrm{~mm}$ in diameter) were taken per plant for three biological replicates per time point. Samples for days 0 and 3 were taken from different plants. The experiments were repeated three times and the figures in this article depict results from a representative experiment. The results of each replicate were averaged using the JMP Pro 12 statistical program (https://www.jmp.com/en_us/software/data-analysis-software. $\mathrm{html}$ ) and analyzed as described previously (Hind et al. 2016).

Virulence assays with tomato. The strains were grown in $\mathrm{KB}$ semiselective medium and prepared for vacuum infiltration using a protocol described previously (Kraus et al. 2016). Strains were diluted in $10 \mathrm{mM} \mathrm{MgCl}_{2}$ to a final concentration of $5 \times 10^{4} \mathrm{CFU} / \mathrm{ml}$. Four-week-old plants were vacuum infiltrated and three leaf disc samples ( $7 \mathrm{~mm}$ in diameter) were taken at days 0,2 , and 5 to quantify bacterial populations. Samples for the different time points were taken from the same plants but different leaflets. The experiments were repeated three times and the figures depict results from a representative experiment using four biological replicates per strain. Photographs for each technical replicate were taken 7 days after infiltration. Analyses were performed using the JMP Pro 12 statistical program, as described previously (Hind et al. 2016).

Detection of effector genes in the $P$. syringae pv. tomato strains. Strains of $P$. syringae pv. tomato were grown in liquid KB medium overnight. The next day, $100-\mu \mathrm{l}$ aliquots were lysed for $10 \mathrm{~min}$ at $90^{\circ} \mathrm{C}$ followed by a 5 -min $16,000 \times g$ centrifugation. The supernatant $(1 \mu \mathrm{l})$ was used as the template to perform a standard GoTaq PCR protocol (Promega Corp.). The $10-\mu l$ reaction contained $1 \times$ GoTaq buffer, $0.5 \mathrm{U}$ of GoTaq DNA Polymerase, $0.1 \mathrm{mM}$ dNTP, $0.25 \mu \mathrm{M}$ forward primer, $0.25 \mu \mathrm{M}$ reverse primer, and $1 \mu \mathrm{l}$ of the boiled supernatant.

The following polymerase chain reaction (PCR) program was used: $95^{\circ} \mathrm{C}$ for $5 \mathrm{~min}$; followed by 35 cycles at $95^{\circ} \mathrm{C}$ for $30 \mathrm{~s}$, $55^{\circ} \mathrm{C}$ for $30 \mathrm{~s}$, and $72^{\circ} \mathrm{C}$ for $1 \mathrm{~min} / \mathrm{kb}$; and a final extension step of $72^{\circ} \mathrm{C}$ for $5 \mathrm{~min}$. PCR products were electrophoresed for $45 \mathrm{~min}$ at $110 \mathrm{~V}$ on a $1 \%$ agarose gel stained with RedSafe Nucleic Acid Staining Solution (Intron Biotechnology). The effector genes tested for classification of $P$. syringae pv. tomato included hopR (800 bp; diagnostic for $P$. syringae pv. tomato) avrA and hopWl (775 and $787 \mathrm{bp}$, respectively; diagnostic for race $1 P$. syringae pv. tomato strains), and hopN1 (727 bp; characteristic of race 0 P. syringae pv. tomato strains) (Jones et al. 2015). Effector genes avrPto (495 bp), avrPto $B_{\mathrm{DC} 3000}(838 \mathrm{bp})$, and $a v r P t o B_{\mathrm{T} 1}(869 \mathrm{bp})$ were amplified and sequenced to distinguish between race 0 and race 1 of $P$. syringae pv. tomato. The sequences of the primers used in this study are provided in Supplementary Table S1.

RNA extraction and cDNA synthesis for reverse-transcription PCR. Bacterial cultures were grown in $h r p$-inducing minimal medium-50 mM phosphate buffer ( $\mathrm{pH} 5.7), 7.6 \mathrm{mM}\left(\mathrm{NH}_{4}\right)_{2} \mathrm{SO}_{4}$, $1.7 \mathrm{mM} \mathrm{MgCl} 2,1.7 \mathrm{mM} \mathrm{NaCl}$, and $10 \mathrm{mM}$ fructose (Huynh et al. 1989) - to a final concentration of $2 \times 10^{8} \mathrm{CFU} / \mathrm{ml}$. RNA was extracted following the RNAprotect Bacteria Reagent Handbook (Qiagen) protocol. Isolated RNA was treated with Turbo DNase from Ambion according to the manufacturer's instructions (Thermo Scientific). A total of $600 \mathrm{ng}$ of RNA was used for cDNA synthesis with random hexamer primers with a Thermo Scientific RevertAid FirstStrand cDNA Synthesis Kit (Thermo Scientific).

$P$. syringae pv. tomato protein expression. Cultures of $P$. syringae pv. tomato grown on $\mathrm{KB}$ semiselective medium plates for 2 days were resuspended to either a final optical density at $600 \mathrm{~nm}$ $\left(\mathrm{OD}_{600}\right)=0.4$ in $5 \mathrm{ml}$ of $h r p$-inducing liquid minimal or to
$\mathrm{OD}_{600}=0.1$ in $\mathrm{KB}$ semiselective medium containing appropriate antibiotics. Bacterial cultures were incubated at room temperature at $220 \mathrm{rpm}$ in the liquid medium. The next day, the $\mathrm{OD}_{600}$ was adjusted to 0.5 . Each bacterial culture $(1 \mathrm{ml})$ was centrifuged, resuspended in water, and centrifuged again. Washed bacterial pellets were boiled for $10 \mathrm{~min}$ in $100 \mu \mathrm{l}$ of Laemmli buffer $(20 \mathrm{mM}$ Tris, $1 \%$ sodium dodecyl sulfate [SDS], $0.05 \%$ bromphenol blue, and $10 \%$ glycerol [pH 6.8]) and $5 \mu \mathrm{l}$ was used for immunoblot analysis (Laemmli 1970).

Immunoblot assay. SDS-polyacrylamide gel electrophoresis (PAGE) and subsequent transfer to polyvinylidene difluoride (PVDF) membranes for Western blotting was performed according to standard procedures (Harlow and Lane 1988). AvrPtoB antibody was affinity purified from antiserum by PVDF transfer before use for detection. Specifically, AvrPtoB protein was expressed in Escherichia coli and resolved on $8 \%$ SDS-PAGE. After transfer, the PVDF membrane was stained with Ponceau $\mathrm{S}$ and the strip containing the antigen protein was cut out and rinsed with Tris-buffered saline and $0.1 \%$ Tween 20 (TBS-T) until the membrane was no longer pink. After blocking the membrane with $5 \%$ milk/TBS-T for $1 \mathrm{~h}$ at room temperature with gentle

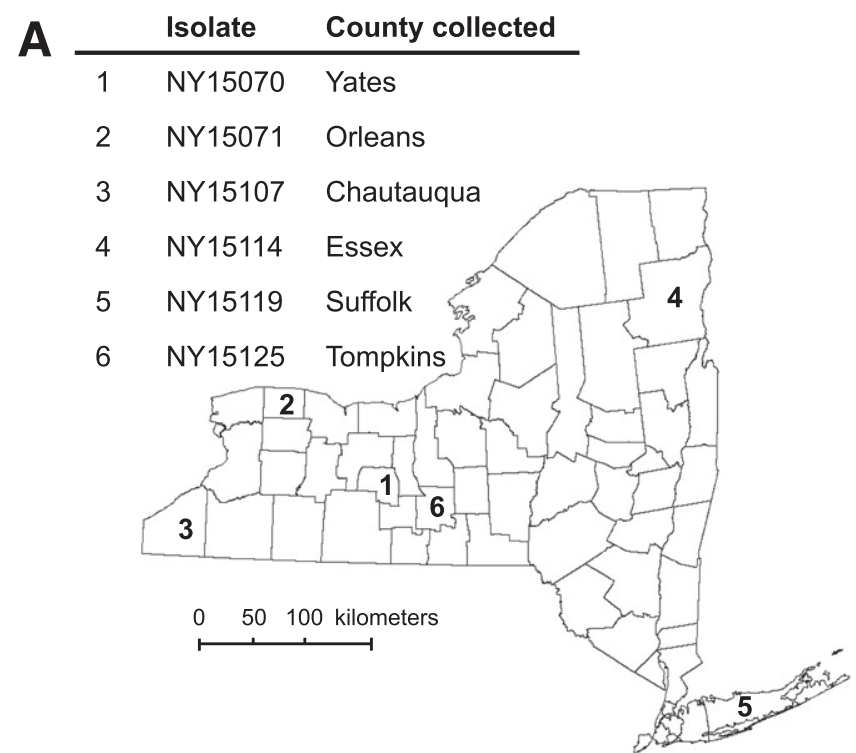

\begin{tabular}{r|cccc} 
B Specific to: & Pst & Race 0 & \multicolumn{2}{c}{ Race 1 } \\
\hline Effector: & hopR & hopN1 & avrA & hopW1 \\
\hline DC3000 & + & + & - & - \\
NY15070 & + & - & + & + \\
NY15071 & + & - & + & + \\
NY15107 & + & - & + & + \\
NY15114 & + & - & + & + \\
NY15119 & + & - & + & + \\
NY15125 & + & - & + & + \\
T1 & + & - & + & + \\
NYT1 & + & - & + & +
\end{tabular}

Fig. 1. Collection sites of Pseudomonas syringae pv. tomato strains and diagnostic polymerase chain reaction (PCR) analysis. A, Map of New York state showing the counties in which $P$. syringae pv. tomato strains were collected from infected tomato plants in summer 2015. B, PCR analysis using primers diagnostic for $P$. syringae pv. tomato or for specific type III effectors that allow discrimination between race 0 and race 1 isolates of $P$. syringae pv. tomato. Symbols: + indicates gene was detected by PCR and - indicates gene was not detected by PCR. DC3000 is a representative race 0 strain and $\mathrm{T} 1$ and NYT1 are representative race 1 strains. 
rocking, the membrane was cut into small pieces and inserted into a $15-\mathrm{ml}$ centrifuge tube containing $2 \mathrm{ml}$ of diluted serum with $8 \mathrm{ml}$ of TBS. The centrifuge tube was incubated overnight at $4^{\circ} \mathrm{C}$. The next day, the blot was washed three times with TBS-T and bound antibody was eluted with $2 \mathrm{ml}$ glycine buffer $(0.1 \mathrm{M}$ glycine $+\mathrm{HCl}, \mathrm{pH} 2.4)$ by vortexing for $1 \mathrm{~min}$, incubating for $2 \mathrm{~min}$ on a rotator, and vortexing again for $1 \mathrm{~min}$. A volume of $200 \mu \mathrm{l}$ of $1 \mathrm{M}$ Tris (pH 8.0) was added to the collected liquid for neutralization. Elution and neutralization steps were repeated a total of three times. AvrPtoB antibody was concentrated using Centrifugal Filter Units (Millipore), following the manufacturer's instructions. For the immunoblot assay, purified AvrPtoB antibody was used at a concentration of 1:1,000. For AvrPto, the antisera containing the polyclonal AvrPto antibody was used at a concentration of 1:20,000. Secondary goat antirabbit immunoglobulin G HRP conjugate at a dilution of 1:20,000 was used for detection (Promega Corp.).

Construction of the NY151144avrPto mutant. Deletion of avrPto from NY15114 was performed by biparental mating using the suicide vector $\mathrm{pK} 18$ mobsacB transformed into E. coli $\mathrm{S} 17-1$. A DNA fragment comprising $980 \mathrm{bp}$ upstream of the avrPto sequence (including the start codon) and the beginning of the coding sequence was fused to a DNA fragment 1,103 bp downstream (including the stop codon) of the avrPto gene by PCR. XbaI sites were included in

A

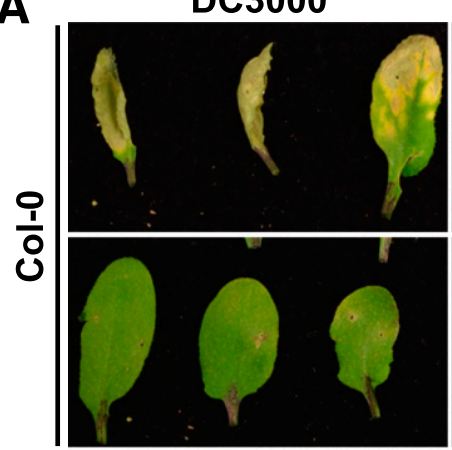

NY15114

B

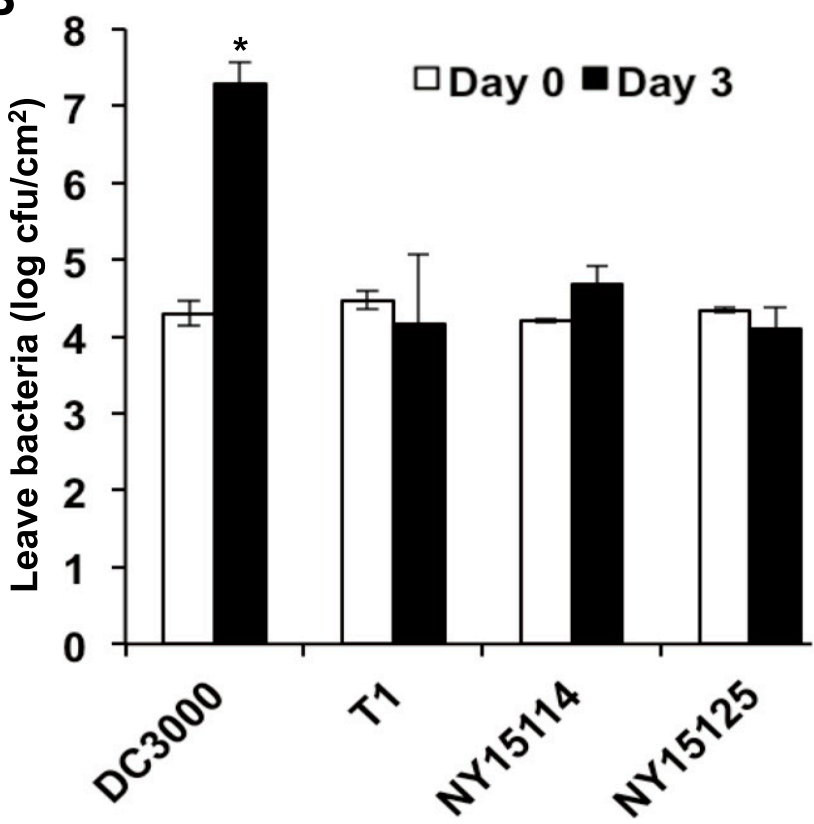

Fig. 2. New York strains do not cause disease on Arabidopsis thaliana Col-0. A, Arabidopsis Col-0 leaves were syringe infiltrated with each strain at $5 \times 10^{4}$ $\mathrm{CFU} / \mathrm{ml}$ and photographs were taken 7 days after inoculation. B, Leaf samples were taken at 0 and 3 days after inoculation and bacterial populations were determined. Data are presented as mean \pm standard deviation. The asterisk indicates a significant difference $(P<0.0006)$ between day 0 and day 3 based on a Welch's test (unequal variance $t$ test). Experiments were performed three times with similar results. both outer oligos, resulting in a DNA fragment with $X b a \mathrm{I}$ restriction sites at both ends. Deletions created using pK18mobsacB and $P$. syringae pv. tomato mutant selection were performed as described previously (Kvitko and Collmer 2011), with the following change. The $P$. syringae pv. tomato strain was grown on $\mathrm{KB}$ semiselective medium plates supplemented with glutamine at $16 \mathrm{~g} /$ liter for 2 days at $30^{\circ} \mathrm{C}$ to reduce production of exopolysaccharides that might interfere with the mating process (Martin et al. 1988) instead of in liquid KB semiselective medium. E. coli and $P$. syringae pv. tomato strains were conjugated on sterile nitrocellulose squares on $\mathrm{KB}$ medium (KBM) plates and incubated for 2 days at $30^{\circ} \mathrm{C}$. Bacteria grown on the nitrocellulose squares were resuspended in $200 \mu \mathrm{l}$ of $\mathrm{KBM}$ and plated on minimal mannitol-glutamate (MG) medium (mannitol at $10 \mathrm{~g} / \mathrm{liter}, \mathrm{L}-$ glutamic acid at $2 \mathrm{~g} / \mathrm{liter}, \mathrm{KH}_{2} \mathrm{PO}_{4}$ at $0.5 \mathrm{~g} / \mathrm{liter}, \mathrm{NaCl}$ at $0.2 \mathrm{~g} / \mathrm{liter}$, and $\mathrm{MgSO}_{4}$ at $0.2 \mathrm{~g} /$ liter; final $\left.\mathrm{pH} 7\right)+$ kanamycin (Kan) at $50 \mathrm{mg} /$ $\mathrm{ml}$ plates and incubated for 3 to 6 days at $30^{\circ} \mathrm{C}$ (Bronstein et al. 2008). MG medium selects against $E$. coli and the addition of Kan selects for $P$. syringae pv. tomato merodiploid transconjugates. Approximately 10 single colonies were streaked on KBM Kan plates and incubated overnight at $30^{\circ} \mathrm{C}$. The next day, single colonies were grown at room temperature in $3 \mathrm{ml}$ of liquid KBM Kan. The following morning, a 1:100 and 1:1,000 dilution of the overnight culture was plated on KBM Kan and $10 \%$ sucrose (Suc) to counterselect the integration and incubated for 2 days at $30^{\circ} \mathrm{C}$. Finally, 25 single colonies were patched from the Kan Suc KBM plate onto KBM and KBM Kan plates. Colonies that grew on KBM and not on KBM Kan were selected for further characterization. Deletion of the avrPto gene was confirmed by both PCR and Sanger sequencing.

\section{Results}

Diagnostic effector genes indicate that 2015 New York $P$. syringae pv. tomato isolates are race 1 strains. Between 5 and 10 $P$. syringae pv. tomato isolates were collected from outbreaks of bacterial speck disease in tomato fields in each of six New York counties (Fig. 1A). Isolates were single-colony purified and checked for fluorescence on KB semiselective medium (King et al. 1954) under ultraviolet light as a first classification step for $P$. syringae pv. tomato (not shown). The six $P$. syringae pv. tomato strains chosen for this study were representative of each collection site based on colony morphology and the $16 \mathrm{~S}-23 \mathrm{~S}$ ribosomal DNA spacer region sequence.

The $P$. syringae pv. tomato strains were next examined by PCR using primers that specifically amplify sequences from effectors that discriminate between group I (associated with tomato) and other $P$. syringae groups (nonpathogens of tomato), as well as other tomato bacterial pathogens such as Xanthomonas perforans and Clavibacter michiganensis subsp. michiganensis. Also employed were primers that amplify effector sequences that are diagnostic of race 0 and race $1 P$. syringae pv. tomato strains. All primers used were described previously (Jones et al. 2015). All of the New York strains belong to group I $P$. syringae pv. tomato, as demonstrated by the presence of hopR (Fig. 1B). Furthermore, avrA and hopWl, which are present in other race 1 strains such as T1 and NYT1 but not race 0 strains, were present in all of the New York strains (Fig. 1B). An hopN1 sequence was amplified exclusively from the race 0 strain DC3000 (Fig. 1B). Based on these PCR diagnostic tests, the 2015 New York strains appeared most similar to race 1 strains. From the six strains, NY15114 isolated in Essex County and NY15125 isolated in Tompkins County were chosen as representative strains for further molecular characterization.

$P$. syringae pv. tomato strains isolated in New York are nonpathogenic on Arabidopsis, similar to other known race $1 P$. syringae pv. tomato strains. To date, only DC 3000 and $P$. syringae pv. maculicula strains are known to be capable of infecting A. thaliana accessions, including Col-0 (Almeida et al. 2009; Yan et al. 2008). We tested NY15114 and NY15125 for their ability to infect, proliferate in, and cause symptoms on Arabidopsis Col-0 plants. At 1 week after infiltration, both strains were similar to T1 in being unable to cause disease on Arabidopsis leaves (Fig. 2A). Tissue was sampled at day 0 and day 3 to measure the size of the bacterial populations. As expected, the New York strains and T1 grew poorly in 
Arabidopsis. In contrast, DC3000 caused severe symptoms and multiplied significantly by day 3 (Fig. 2B). Thus, the New York strains are similar to other race 1 strains in being nonpathogenic on Arabidopsis.

$P$. syringae pv. tomato strains collected in New York are recognized by Pto/Prf but overcome this resistance at later time points. To test whether Pto/Prf confers resistance to the New York isolates, we vacuum infiltrated each New York strain into 4-weekold 'Rio Grande'-PtoR plants (RG-PtoR) expressing Pto/Prf from Solanum pimpinellifolium and RG-prf3 plants (RG-PtoR with a null mutation in Prf). P. syringae pv. tomato strains DC3000 (race 0), DC3000 $a v r P t o \Delta a v r P t o B$ (lacking AvrPto and AvrPtoB), and T1 and NYT1 (both race 1) were used as controls. Leaf tissue samples were taken at 0,2 , and 5 days after infiltration to determine the size of the bacterial populations. By day 2, each New York strain reached a population size that was intermediate between DC3000 and the P. syringae pv. tomato strains T1, NYT1, and DC3000 $a$ avrPto $\triangle a v r P t o B$ (Fig. 3A). However, unexpectedly, at day 5 , the New York strains reached population sizes similar

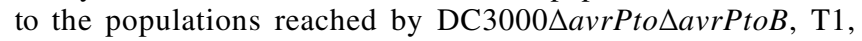
and NYT1 on day 2. No samples were collected at day 5 for DC3000_avrPto $\triangle a v r P t o B$, T1, and NYT1 strains, because the tissue
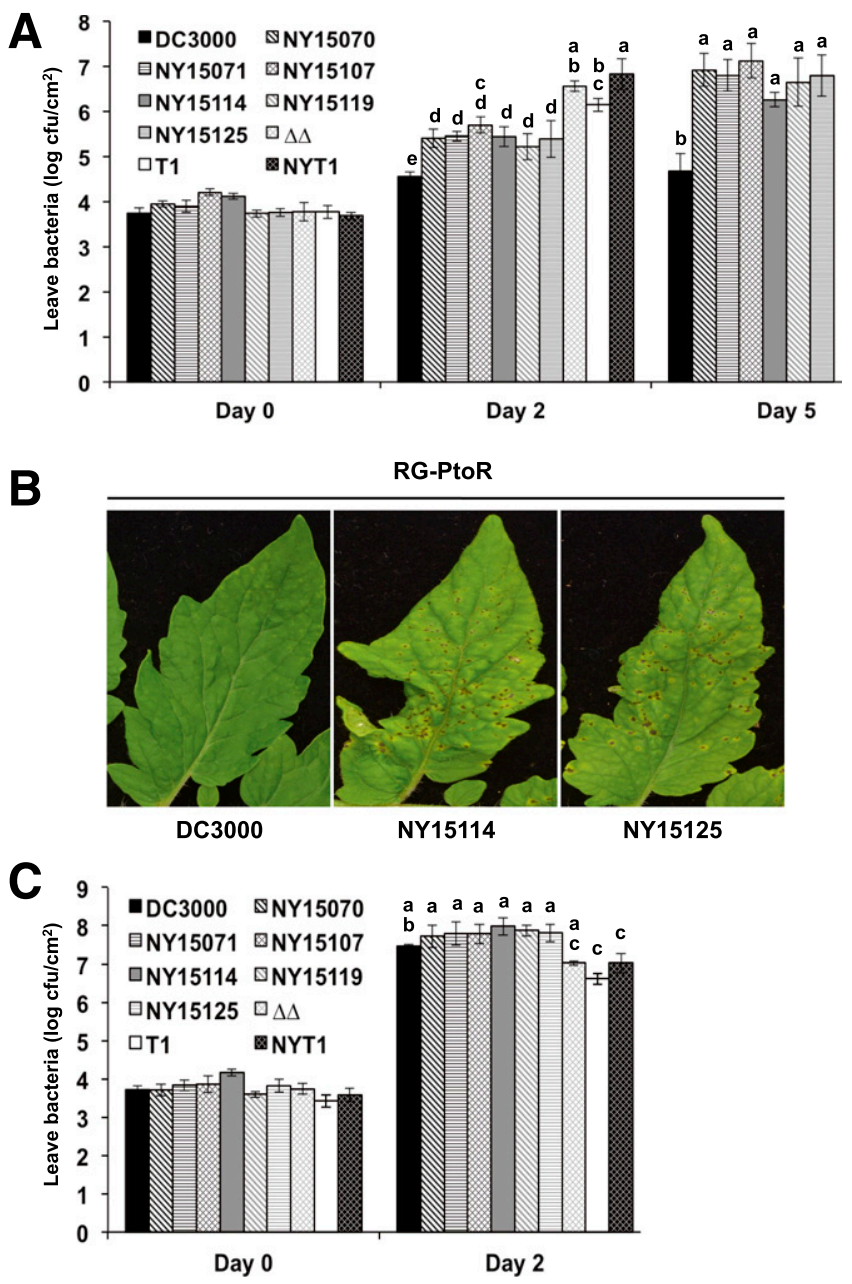

Fig. 3. Pseudomonas syringae pv. tomato strains isolated in New York grow to intermediate population levels on tomato plants with a functional Pto/Prf pathway as compared with race 0 and race 1 strains. A, RG-PtoR plants (with a functional Pto or Prf pathway) or C, RG-prf3 plants (having a mutation in Prf) were vacuum infiltrated with the indicated $P$. syringae $\mathrm{pv}$. tomato strains at a final concentration of $5 \times 10^{4} \mathrm{CFU} / \mathrm{ml}$ and bacterial populations were measured at days 0,2 , and (when possible) 5 after inoculation. Results are shown as the mean of four samples, including standard deviation. Different letters indicate significant differences $(P$ value $<0.05)$ based on a one-way analysis of variance followed by Tukey's honestly significant difference post hoc test (equal variance). B, Photographs of representative leaves were taken 7 days after vacuum infiltration of RG-PtoR plants with the strain indicated. was too necrotic. By day 7, leaves inoculated with the New York strains showed clear symptoms of bacterial speck disease (Fig. 3B). In contrast, no additional growth or symptom development was detected in plants infiltrated with DC3000 (Fig. 3A and B). These observations suggested that, under these conditions (vacuum infiltration of $P$. syringae pv. tomato), Pto/Prf recognize the New York strains but that this resistance is overcome after day 2 . In agreement with this possibility, bacterial populations for all the $P$. syringae pv. tomato strains reached high levels in RG-prf3 tomato plants after just 2 days (Fig. 3C), leading to disease symptoms as early as 3 days after inoculation (not shown).

New York strains express both the avrPto and avrPtoB genes but only accumulate AvrPto protein. The lower growth at day 2 of the New York strains on the Pto/Prf-expressing tomato variety RG-PtoR as compared with the race 1 strains and DC3000 $\Delta a v r P t o \Delta a v r P t o B$ suggested that the strains might express avrPto or $a v r P t o B$. Using sets of specific primers to amplify avrPto and a fragment of $a v r P t o B$ that differentiates between $a v r P t o B$ in DC3000 and T1, we found that NY15114 and NY15125 contain the genes for both effectors (Fig. 4A). The avrPto DNA sequence of both New York strains is identical to avrPto in strain JL1065

A

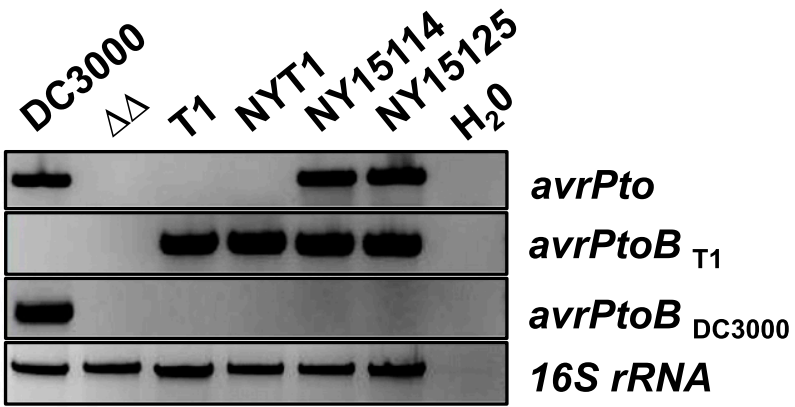

B
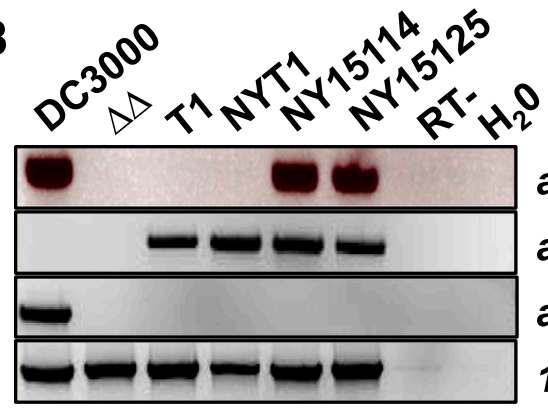

avrPto avrPtoB $_{\mathrm{T} 1}$ avrPtoB $\mathrm{DC} 3000$ 16S rRNA

C

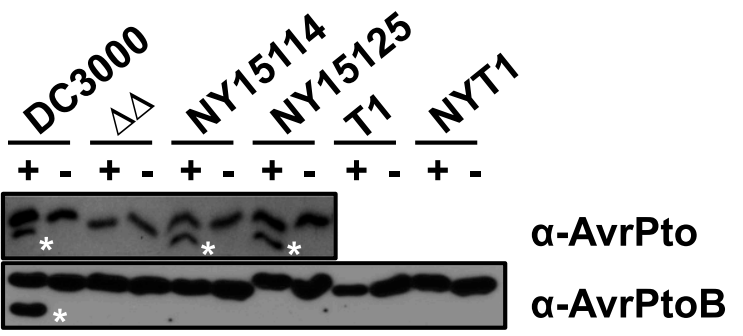

Fig. 4. New York strains produce transcripts of avrPto and avrPtoB but only AvrPto protein accumulates in the bacterial cell. A, Polymerase chain reaction (PCR) of genomic DNA detects the presence of avrPto and avrPtoB genes in the $2015 \mathrm{New}$ York strains. DC3000 and DC3000 $\Delta a v r P t o / \Delta a v r P t o B(\Delta \Delta)$ were used as positive and negative controls, respectively, for these genes. The $P$. syringae pv. tomato strains T1 and NYT1 are other controls known to have the avrPtoB gene but not the avrPto gene. B, Reverse-transcription PCR analysis to detect transcripts of the effectors. The CDNA was synthesized from RNA isolated from bacteria grown in hrp-inducing medium (HrpMM). Primers amplifying 16S ribosomal RNA were used as an internal control (A and B). C, Detection of AvrPto and AvrPtoB protein accumulation by Western blotting using antibodies raised against each protein. Bacteria were grown in HrpMM overnight. A white asterisk indicates an adjacent protein band with the correct molecular weight for AvrPto or AvrPtoB. A nonspecific band with a higher molecular weight is observed and serves as a control for equal loading in each lane. 
(Ronald et al. 1992), and this allele encodes a protein differing in just four amino acids from AvrPto expressed by DC3000 (Supplementary Fig. S1). We obtained an amplicon for $a v r P t o B$ from the New York strains only when using the T1-specific $a v r P t o B$ primers. We additionally amplified and sequenced the complete $a v r P t o B$ gene from both strains, and found that the New York $a v r P t o B$ DNA sequence is $100 \%$ identical to the $a v r P t o B_{\mathrm{T} 1}$ allele.

To determine whether these two effector genes are transcribed, we grew the $P$. syringae pv. tomato strains in hrp-inducing minimal medium (HrpMM) to mimic plant infection, thereby inducing effector gene expression. RNA was extracted and subjected to cDNA synthesis using random hexamer primers. The primers previously tested on DNA
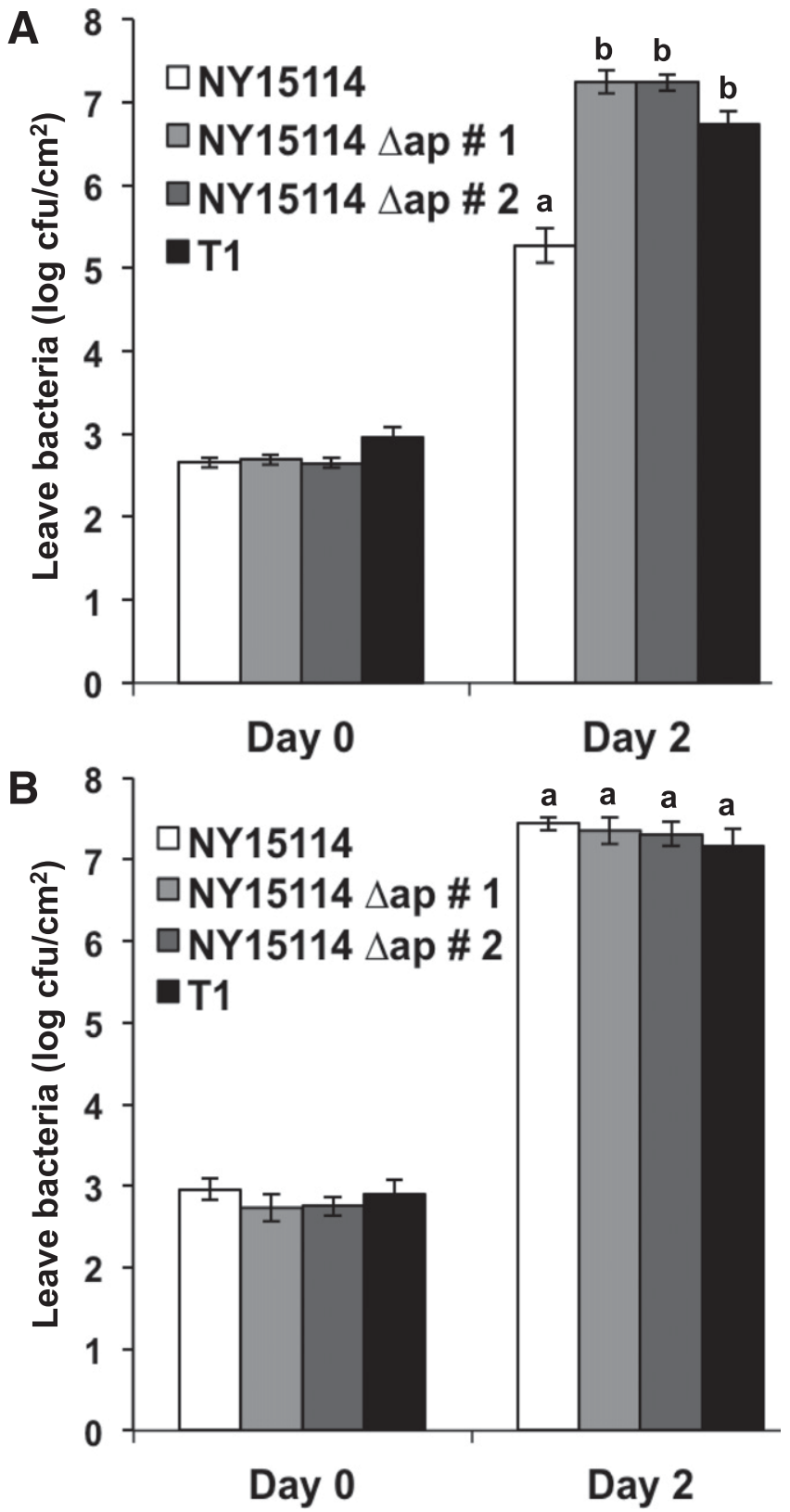

Fig. 5. Deletion of avrPto from NY15114 allows the strain to grow to a higher population level in leaves of RG-PtoR without affecting its ability to grow in leaves of RG-prf3. A, RG-PtoR and B, RG-prf3 plants were vacuum infiltrated with $5 \times$ $10^{4} \mathrm{CFU} / \mathrm{ml}$ and bacterial populations were measured on day 0 and day 2 after infiltration. Results with two independent NY15114 $\Delta$ avrPto mutant strains are shown as the mean of four samples \pm standard deviation. Different letters indicate significant differences $(P$ value $<0.05)$ between the samples. For A, a Steel-Dwass All Pairs test for nonparametric data were performed, whereas $B$ is based on a one-way analysis of variance followed by Tukey's honestly significant difference post hoc test (equal variance). Experiments were performed twice with similar results. were used for a reverse-transcription (RT)-PCR. Both genes were expressed under inducing conditions in NY15114 and NY15125 similar to DC3000 (Fig. 4B). Primers amplifying the $16 S$ RNA were used as a control for DNA and RNA quality (Fig. 4A and B).

It has been previously shown that strain $\mathrm{T} 1$ and certain other race 1 P. syringae pv. tomato strains collected in California (such as A9, 19, $838-8,838-16,22$, and 23) posttranscriptionally suppress accumulation of AvrPtoB protein by an unknown mechanism, thereby evading Pto/Prf-mediated recognition of this effector (Kunkeaw et al. 2010; Lin et al. 2006). Because the $\operatorname{avrPtoB}$ sequences in the New York $P$. syringae pv. tomato strains are identical to those of $\mathrm{T} 1$ and NYT1 strains, we tested whether this is also the case in NY15114 and NY15125. We grew the $P$. syringae pv. tomato strains in HrpMM medium and assayed for effector protein accumulation using an antibody raised specifically against AvrPtoB. The protein was detected only in DC3000 (Fig. 4C) and, therefore, we conclude that, although NY15114 and NY15125 encode an intact avrPtoB gene, they do not accumulate AvrPtoB protein, identical to T1 and NYT1. Experiments using an AvrPto-specific antibody demonstrated that protein of this effector accumulated in the two New York $P$. syringae pv. tomato samples, similar to wild-type DC3000 when cultured in HrpMM medium (Fig. 4C).

Deletion of avrPto abolishes recognition of NY15114 by Pto/ Prf in RG-PtoR tomato plants without affecting virulence. The presence of AvrPto protein in the New York strains could account for the Pto/Prf-mediated suppression of growth of the New York strains that we observed 2 days after inoculation (Fig. 3A). To test this hypothesis, we developed two independent NY15114 avrPto mutants and examined their ability to grow in RG-PtoR and

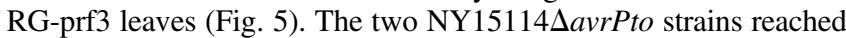
populations comparable with those of T1 on RG-PtoR, whereas wildtype NY15114, as observed previously, grew to only intermediate levels on RG-PtoR (Fig. 5A). These results indicate that the AvrPto protein in NY15114 is recognized by Pto/Prf. On tomato PtoR-prf3 plants which lack a functional Pto/Prf pathway, the two NY15114 a avrPto strains reached populations comparable with those of wild-type NY15114 and T1 (Fig. 5B).

$P$. syringae pv. tomato strain K40 exhibits the same intermediate growth phenotype on RG-PtoR plants as the New York

isolates. We next wished to test whether any other $P$. syringae pv. tomato strains exhibited similar growth characteristics on RG-PtoR as that observed with the New York strains. We tested three strains available in our lab (Max13, K40, and NCPPB1108) that have both avrPto and avrPtoB. Plants were vacuum infiltrated and leaf samples taken at days 0 and 5 after infiltration of RG-PtoR plants and at day 2 for RG-prf3 plants. Max13 and NCPPB1108 grew to the same population level as DC3000 on RG-PtoR plants (Fig. 6A), indicating that Pto/Prf fully recognize these strains and inhibit bacterial growth. However, K40, a strain that was isolated in Virginia in 2005, grew to the same population size as NY15114 (Fig. 6A), resulting in later symptom development similar to the NY isolates. All tested strains grew to high levels on susceptible RG-prf3 plants, confirming their ability to infect tomato plants and grow to high population levels when not recognized by Pto/Prf (Fig. 6B).

\section{Discussion}

The recent outbreaks of bacterial speck across New York have highlighted the continued importance of this disease to tomato growers and the lack of genetic resistance in most fresh-market tomato varieties. The outbreaks also presented the opportunity to investigate the characteristics of the $P$. syringae pv. tomato strains involved with the aim of determining whether or not the Pto/Prf locus would be worth deploying in fresh-market tomato in this area. In our initial experiments using previously developed diagnostic effector sequences (Jones et al. 2015), all of the New York isolates had specific effectors indicative of race 1 strains. In common with other race 1 strains, the New York isolates were also unable to multiply or cause disease symptoms in Arabidopsis. These observations were not unexpected because race 1 strains are known to be widespread (Cai et al. 2011; Kunkeaw et al. 2010). However, inoculation of the strains 
on tomato unexpectedly indicated they were recognized by Pto/Prf, suggesting that they likely encode avrPto or avrPtoB.

The presence of avrPto or $a v r P t o B$ originally indicated that a strain would be race 0 (would be recognized by Pto/Prf). However, it is now known that some strains have avrPto but the gene has mutations that prevent Pto/Prf from recognizing its encoded protein (Kunkeaw et al. 2010). Other strains have avrPtoB and, although the corresponding transcript is present, no AvrPtoB protein is detectable (Kunkeaw et al. 2010; Lin et al. 2006). If the AvrPtoB protein is present at a low level in these strains, it is not sufficient to allow Pto/ Prf to activate an effective defense response. The mechanism by which some $P$. syringae pv. tomato strains prevent the accumulation of AvrPtoB protein is unknown but it may have evolved to allow evasion of recognition by tomato varieties expressing Pto/Prf while preserving the potential for restoring virulence associated with this effector.

Our characterization of the New York strains revealed that they have both avrPto and $a v r P t o B$ but only express AvrPto protein at a detectable level. Deletion of avrPto from a representative New York strain showed that it is, indeed, responsible for causing the decreased growth in Pto/Prf-expressing tomato leaves and, therefore, is responsible for the recognition by Pto/Prf. Based on these observations these strains can be regarded as race 0 , although the intermediate growth phenotype distinguishes them from typical race 0 strains. Two $P$. syringae pv. tomato strains that were recently characterized from collections in western North Carolina from fresh-market tomato also had avrPto and avrPtoB, suggesting that race 0 strains are perhaps more common than expected in the eastern United States (Veluchamy et al. 2014).

The most unusual characteristic of the New York strains is the intermediate population size they obtained 2 days after inoculation in Pto/Prf-expressing tomato leaves compared with typical race 0 and 1 strains. Unexpectedly for race 0 strains, 5 days after inoculation, the populations of the New York strains reached levels comparable with race 1 strains after 2 days and caused symptoms on leaves and stems but did not kill the plant, as seen with T1 or NYT1. These experiments were performed in environmentally controlled growth chambers using vacuum infiltration and, thus, have the potential of detecting more subtle differences than would be observed in field experiments. We do not currently have an explanation for this intermediate growth phenotype and the subsequent overcoming of Pto/ Prf-mediated resistance at day 5. It seems unlikely that it is due to a low expression level of AvrPto because our experiments detected protein accumulation of this effector in the New York strains similar to that seen in DC3000 (although it is possible that less AvrPto protein gets translocated into the plant cells). An alternative, intriguing hypothesis is that the New York strains and K40 express another factor that suppresses the Pto- or Prf-mediated immune response. This ETI-suppressing factor could be a type III effector, as has been reported to occur in other cases (Guo et al. 2009; Jackson et al. 1999; Wei et al. 2015). In the future, we will pursue this possibility by obtaining the genome sequences of multiple New York isolates and determining whether they contain a unique effector that is also present in $\mathrm{K} 40$.

Although the $P$. syringae pv. tomato isolates were collected from diverse geographical areas across New York, the various molecular and virulence-associated phenotypes we assayed suggest that they might be highly similar at the genome level. A possible explanation for this uniformity could be that all the strains derive from a common supplier of tomato seed or transplants. Examples of such a scenario have been documented in the past (McCarter et al. 1983). To support this hypothesis, a survey of affected growers would be required. Another possibility is that a uniform $P$. syringae pv. tomato population exists naturally in New York. Consistent with this, the NY15114 strain from Tompkins County did not originate in a commercial tomato grower's field but, instead, was isolated from a Cornell University research farm. The seed used had been collected from plants grown in a research greenhouse over many generations and were not sourced from an outside supplier. Because no bacterial speck occurred in the greenhouse, the occurrence of the $P$. syringae $\mathrm{pv}$. tomato population in the environment is a possible, although currently unsubstantiated, explanation for this infection.

The field from which NY15114 was isolated did not contain any Pto/Prf-expressing varieties and, thus, further investigation is needed to test whether the intermediate resistance we observed toward the New York strains would provide some degree of resistance in the field, as it does for typical race 0 strains. In 2016, we conducted a pilot field trial where we spray inoculated NY15114 onto RG-PtoR (resistant) and RG-prf3 (susceptible) tomato lines at the same Cornell
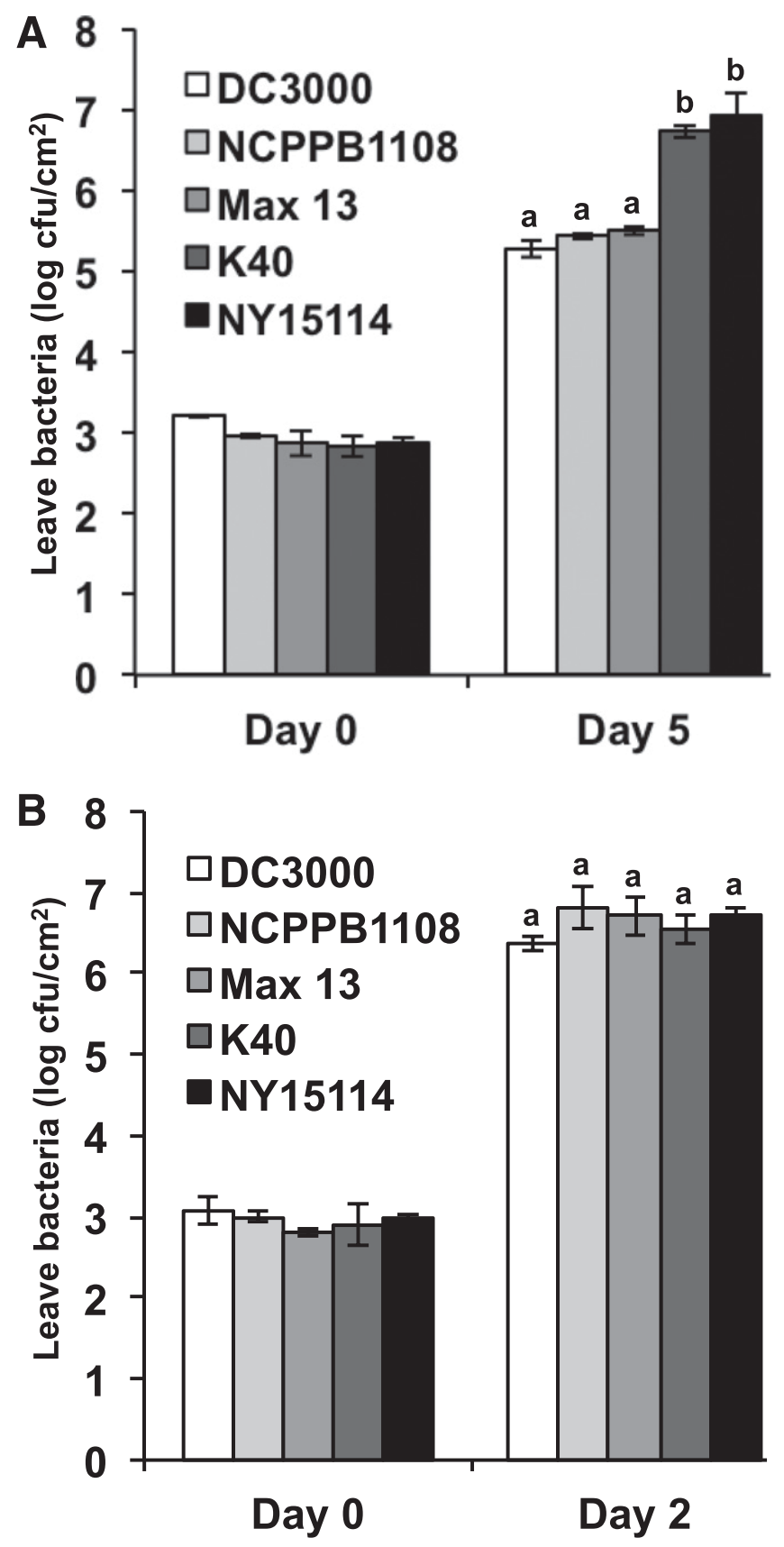

Fig. 6. Pseudomonas syringae pv. tomato strain $\mathrm{K} 40$ shows the same intermediate growth phenotype as the 2015 New York P. syringae pv. tomato strains. Several $P$. syringae pv. tomato strains with sequenced genomes and with a functional AvrPto but lacking AvrPtoB expression were vacuum infiltrated into A, RG-PtoR or B, RG-prf3 plants at $5 \times 10^{4} \mathrm{CFU} / \mathrm{ml}$. Bacterial populations were measured at 0 and 5 days after infiltration for RG-PtoR and at 0 and 2 days after infiltration for RG-prf3 plants. Error bars indicate standard deviations for three replicates. Different letters indicate significant differences $(P$ value $<0.05)$. For A, a Steel-Dwass All Pairs test for nonparametric data were performed, whereas $B$ is based on a oneway analysis of variance followed by Tukey's honestly significant difference post hoc test (equal variance). Experiments were performed three times with similar results. 
research farm where this strain was collected. Although the summer was hot and dry and not conducive to bacterial speck development, we did observe some symptoms on leaves, stems, and fruit; these occurred only on the susceptible line, while Pto/Prf-expressing plants remained disease-free. If future experiments support these preliminary observations, it would indicate that introgression of Pto/Prf into tomato varieties might provide a viable strategy to control or at least lessen the seriousness of bacterial speck outbreaks on freshmarket tomato in this part of the country.

\section{Acknowledgments}

We thank J. Worley and E. Rosenthal for optimizing the P. syringae pv. tomato transformation protocol, J. Mathieu and R. Fahey for critical review of the manuscript, and New York tomato growers for providing leaf samples. No conflict of interest is declared. This work was supported, in part, by National Science Foundation grant number IOS-1546625 (GBM).

\section{Literature Cited}

Abramovitch, R. B., Kim, Y.-J., Chen, S., Dickman, M. B., and Martin, G. B. 2003. Pseudomonas type III effector AvrPtoB induces plant disease susceptibility by inhibition of host programmed cell death. EMBO J. 22:60-69.

Almeida, N. F., Yan, S., Lindeberg, M., Studholme, D. J., Schneider, D. J., Condon, B., Liu, H., Viana, C. J., Warren, A., Evans, C., Kemen, E., Maclean, D., Angot, A., Martin, G. B., Jones, J. D., Collmer, A., Setubal, J. C., and Vinatzer, B. A. 2009. A draft genome sequence of Pseudomonas syringae pv. tomato $\mathrm{T} 1$ reveals a type III effector repertoire significantly divergent from that of Pseudomonas syringae pv. tomato DC3000. Mol. Plant-Microbe Interact. 22:52-62.

Arredondo, C. R., and Davis, R. M. 2000. First report of Pseudomonas syringae pv. tomato race 1 on tomato in California. Plant Dis. 84:371.

Bosch, S. E., Boelema, B. H., Serfontein, J. J., and Swanepoel, A. E. 1990. 'Rotam 4', a multiple disease-resistant fresh-market tomato. HortScience 25: 1313-1314.

Bronstein, P. A., Filiatrault, M. J., Myers, C. R., Rutzke, M., Schneider, D. J., and Cartinhour, S. W. 2008. Global transcriptional responses of Pseudomonas syringae DC3000 to changes in iron bioavailability in vitro. BMC Microbiol. 8:209.

Buell, C. R., Joardar, V., Lindeberg, M., Selengut, J., Paulsen, I. T., Gwinn, M. L., Dodson, R. J., Deboy, R. T., Durkin, A. S., Kolonay, J. F., Madupu, R., Daugherty, S., Brinkac, L., Beanan, M. J., Haft, D. H., Nelson, W. C., Davidsen, T., Zafar, N., Zhou, L., Liu, J., Yuan, Q., Khouri, H., Fedorova, N., Tran, B., Russell, D., Berry, K., Utterback, T., Van Aken, S. E., Feldblyum, T. V., D’Ascenzo, M., Deng, W. L., Ramos, A. R., Alfano, J. R., Cartinhour, S., Chatterjee, A. K., Delaney, T. P., Lazarowitz, S. G., Martin, G. B., Schneider, D. J., Tang, X., Bender, C. L., White, O., Fraser, C. M., and Collmer, A. 2003. The complete genome sequence of the Arabidopsis and tomato pathogen Pseudomonas syringae pv. tomato DC3000. Proc. Natl. Acad. Sci. USA 100:10181-10186.

Buonaurio, R., Stravato, V. M., and Cappelli, C. 1996. Occurrence of Pseudomonas syringae pv. tomato race 1 in Italy on Pto gene-bearing tomato plants. J. Plant Phytopathol. 144:437-440.

Cai, R., Lewis, J., Yan, S., Liu, H., Clarke, C. R., Campanile, F., Almeida, N. F., Studholme, D. J., Lindeberg, M., Schneider, D., Zaccardelli, M., Setubal, J. C., Morales-Lizcano, N. P., Bernal, A., Coaker, G., Baker, C., Bender, C. L., Leman, S., and Vinatzer, B. A. 2011. The plant pathogen Pseudomonas syringae pv. tomato is genetically monomorphic and under strong selection to evade tomato immunity. PLoS Pathog. 7:e1002130.

Guo, M., Tian, F., Wamboldt, Y., and Alfano, J. R. 2009. The majority of the type III effector inventory of Pseudomonas syringae pv. tomato DC3000 can suppress plant immunity. Mol. Plant-Microbe Interact. 22:1069-1080.

Harlow, E., and Lane, D. 1988. Antibodies: A Laboratory Manual. Cold Spring Harbor Laboratory, Cold Spring Harbor, NY.

Hind, S. R., Strickler, S. R., Boyle, P. C., Dunham, D. M., Bao, Z., O’Doherty, I. M., Baccile, J. A., Hoki, J. S., Viox, E. G., Clarke, C. R., Vinatzer, B. A., Schroeder, F. C., and Martin, G. B. 2016. Tomato receptor FLAGELLINSENSING 3 binds flgII-28 and activates the plant immune system. Nat. Plants 2: Article 16128.

Huynh, T. V., Dahlbeck, D., and Staskawicz, B. J. 1989. Bacterial blight of soybean: Regulation of a pathogen gene determining host cultivar specificity. Science 245:1374-1377

Jackson, R. W., Athanassopoulos, E., Tsiamis, G., Mansfield, J. W., Sesma, A., Arnold, D. L., Gibbon, M. J., Murillo, J., Taylor, J. D., and Vivian, A. 1999. Identification of a pathogenicity island, which contains genes for virulence and avirulence, on a large native plasmid in the bean pathogen Pseudomonas syringae pathovar phaseolicola. Proc. Natl. Acad. Sci. USA 96:10875-10880.

Jones, L. A., Saha, S., Collmer, A., Smart, C. D., and Lindeberg, M. 2015. Genome-assisted development of a diagnostic protocol for distinguishing high virulence Pseudomonas syringae pv. tomato strains. Plant Dis. 99: 527-534.

Kim, Y. J., Lin, N.-C., and Martin, G. B. 2002. Two distinct Pseudomonas effector proteins interact with the Pto kinase and activate plant immunity. Cell 109: 589-598.

King, E. O., Ward, M. K., and Raney, D. E. 1954. Two simple media for the demonstration of pyocyanin and fluorescin. J. Lab. Clin. Med. 44:301-307.

Kraus, C. M., Munkvold, K. R., and Martin, G. B. 2016. Natural variation in tomato reveals differences in the recognition of AvrPto and AvrPtoB effectors from Pseudomonas syringae. Mol. Plant 9:639-649.

Kunkeaw, S., Tan, S., and Coaker, G. 2010. Molecular and evolutionary analyses of Pseudomonas syringae pv. tomato race 1. Mol. Plant-Microbe Interact. 23:415-424.

Kvitko, B. H., and Collmer, A. 2011. Construction of Pseudomonas syringae pv. tomato DC3000 mutant and polymutant strains. Pages 109-128 in: Plant Immunity Methods and Protocols, vol. 712. J. M. McDowell, ed. Humana Press, New York.

Laemmli, U. K. 1970. Cleavage of structural proteins during the assembly of the head of bacteriophage T4. Nature 227:680-685.

Lawton, M. B., and MacNeill, B. H. 1986. Occurrence of race 1 of Pseudomonas syringae pv. tomato on field tomato in southwestern Ontario. J. Plant Pathol. 8:85-88.

Lin, N. C., Abramovitch, R. B., Kim, Y. J., and Martin, G. B. 2006. Diverse AvrPtoB homologs from several Pseudomonas syringae pathovars elicit Ptodependent resistance and have similar virulence activities. Appl. Environ. Microbiol. 72:702-712.

Lin, N. C., and Martin, G. B. 2005. An avrPto/avrPtoB mutant of Pseudomonas syringae pv. tomato DC3000 does not elicit Pto-mediated resistance and is less virulent on tomato. Mol. Plant-Microbe Interact. 18:43-51.

Lin, N. C., and Martin, G. B. 2007. Pto- and Prf-mediated recognition of AvrPto and AvrPtoB restricts the ability of diverse Pseudomonas syringae pathovars to infect tomato. Mol. Plant-Microbe Interact. 20:806-815.

Martin, G. B. 2012. Suppression and activation of the plant immune system by Pseudomonas syringae effectors AvrPto and AvrPtoB. Pages 123-154 in: Effectors in Plant-Microbe Interactions. F. Martin and S. Kamoun, eds. Wiley-Blackwell, Oxford, UK.

Martin, G. B., Chapman, K., and Chelm, B. K. 1988. Role of the Bradyrhizobium japonicum ntrC gene product in differential regulation of the glutamine synthetase II gene ( $g$ lnII). J. Bacteriol. 170:5452-5459.

Mathieu, J., Schwizer, S., and Martin, G. B. 2014. Pto kinase binds two domains of AvrPtoB and its proximity to the effector E3 ligase determines if it evades degradation and activates plant immunity. PLoS Pathog. 10:e1004227.

McCarter, S. M., Jones, J. B., Gitaitis, R. D., and Smitley, D. R. 1983. Survival of Pseudomonas syringae pv. tomato in association with tomato seeds, soil, host tissue, and epiphytic weed hosts in Georgia. Phytopathology 73:1393-1398.

McDonald, B. A., and Linde, C. 2002. Pathogen population genetics, evolutionary potential, and durable resistance. Annu. Rev. Pathol. 40:349-379.

Pedley, K. F., and Martin, G. B. 2003. Molecular basis of Pto-mediated resistance to bacterial speck disease in tomato. Annu. Rev. Phytopathol. 41:215-243.

Pitblado, R. E., and MacNeill, B. H. 1983. Genetic basis of resistance to Pseudomonas syringae pv. tomato in field tomatoes. Can. J. Plant Pathol. 5: 251-255.

Ronald, P. C., Salmerson, J. M., Carland, F. M., and Staskawicz, B. J. 1992. The cloned avirulence gene avrPto induces disease resistance in tomato cultivars containing the Pto resistance gene. J. Bacteriol. 174:1604-1611.

Rosebrock, T. R., Zeng, L., Brady, J. J., Abramovitch, R. B., Xiao, F., and Martin, G. B. 2007. A bacterial E3 ubiquitin ligase targets a host protein kinase to disrupt plant immunity. Nature 448:370-374.

Salmeron, J. M., Oldroyd, G. E., Rommens, C. M., Scofield, S. R., Kim, H. S., Lavelle, D. T., Dahlbeck, D., and Staskawicz, B. J. 1996. Tomato Prf is a member of the leucine-rich repeat class of plant disease resistance genes and lies embedded within the Pto kinase gene cluster. Cell 86:123-133.

Shan, L., Thara, V. K., Martin, G. B., Zhou, J. M., and Tang, X. 2000. The Pseudomonas AvrPto protein is differentially recognized by tomato and tobacco and is localized to the plant plasma membrane. Plant Cell 12: 2323-2338.

Veluchamy, S., Hind, S. R., Dunham, D. M., Martin, G. B., and Panthee, D. R. 2014. Natural variation for responsiveness to flg22, flgII-28, and csp22 and Pseudomonas syringae pv. tomato in heirloom tomatoes. PLoS One 9:e106119.

Wei, H.-L., Chakravarthy, S., Mathieu, J., Helmann, T. C., Stodghill, P., Swingle, B., Martin, G. B., and Collmer, A. 2015. Pseudomonas syringae pv. tomato DC3000 Type III secretion effector polymutants reveal an interplay between HopAD1 and AvrPtoB. Cell Host Microbe 17:752-762.

Yan, S., Liu, H., Mohr, T. J., Jenrette, J., Chiodini, R., Zaccardelli, M., Setubal, J. C., and Vinatzer, B. A. 2008. Role of recombination in the evolution of the model plant pathogen Pseudomonas syringae pv. tomato DC3000, a very atypical tomato strain. Appl. Environ. Microbiol. 74:3171-3181.

Yunis, H., Bashan, Y., Okon, Y., and Henis, Y. 1980. Weather dependence, yield losses, and control of bacterial speck of tomato caused by Pseudomonas tomato. Plant Dis. 64:937-939. 